\title{
Intermédialités
}

Histoire et théorie des arts, des lettres et des techniques

Intermediality

History and Theory of the Arts, Literature and Technologies

\section{Repetition, Feedback, and Temporality in Two Compositions by William Basinski}

\section{David Christopher Jackson}

Numéro 33, printemps 2019

restituer (le temps)

rendering (time)

URI : https://id.erudit.org/iderudit/1065021ar

DOI : https://doi.org/10.7202/1065021ar

Aller au sommaire du numéro

Éditeur(s)

Revue intermédialités

ISSN

1920-3136 (numérique)

Découvrir la revue

Citer cet article

Jackson, D. C. (2019). Repetition, Feedback, and Temporality in Two

Compositions by William Basinski. Intermédialités / Intermediality, (33).

https://doi.org/10.7202/1065021ar
Résumé de l'article

Dans cet article, j'examine comment les enregistrements en boucle de William Basinski révèlent et étendent la concurrence esthétique entre la durée technologique, biologique et humaine, la mémoire et la perception de l'objet temporel industriel. Examiner comment le bouclage souligne la circulation d'une composition dans la perception d'un objet médiatique temporel et l'échange entre la mémoire et la machine comme performance et configuration de la sphère mentale poursuit une ligne de pensée qui rassemble les idées sur la répétition de la composition de Basinski, le reformatage sonore de la sphère mentale pour connecter la technologie des compositions lentes et analogiques de Basinski contra le digitalisme accéléré de la vie du $21^{\mathrm{e}}$ siècle. 


\title{
Repetition, Feedback, and Temporality in Two Compositions by William Basinski
}

\author{
DAVID CHRISTOPHER JACKSON
}

\section{INTRODUCTION}

magine a machine on which you could press a button and play back your memories at any time, with the possibility of a potential infinite repetition of sustaining, expanding, delaying, and reverberating your memory in a multiplicity of ways. This hypothetical is of course already part of our contemporary everyday life where memories are stored in databases, recalled through clicking, swiping, and through algorithms - like Facebook's “memories" that prompt you to celebrate on your timeline different milestones (some important and others hilariously banal), or Instagram's "stories" that prompt you to record snippets of your day-to-day experiences and share the audiovisual results with your followers. With increasing frequency our memories are integrating the digitized and databased infoscape, which characterizes contemporary capitalism's exploitation of images, sounds, and processes; furthermore, our memories have come to constitute the fragmented, overexposed, and networked self. Extending Peter Osborne's idea that "everyday life is lived in the medium of the cultural form" and that this process is "at one with commodification" "The loop as a cultural form constitutes a good deal of our everyday experience of contemporary capitalism's reliance on repetition, familiarity, and virality. The same can be said for our media, which uses past cultural forms and narratives and remixes and recreates them for contemporary audiences in new packaging. I situate the analog mnemonic looped performances

${ }^{1}$ Peter Osborne, The Politics of Time: Modernity and Avant-Garde, London and New York, Verso, 1995, p. 197. 
of William Basinski within the rhythm and temporality of everyday life and as an experience through media of this everyday experience

The ability to loop and make time return using magnetic tape has an important history in the development of the avant-garde and runs through experimental music, film, and the increased commodity form of musical instrumentation. This history is part of our cultural experience. The development of recording technologies beyond the graphic score, particularly vinyl records and tape, redefined artistic practices, as evidenced by the early $1930 \mathrm{O}$ turntablism of John Cage and László Moholy-Nagy, the tape splice experiments of Pierre Schafer, Pierre Henry, Daphne Oram, and William S. Burroughs, the development of the recording studio through experimentation by Les Paul, and technological expansion of recording and studio techniques in the r96os in the work of producers like Alan Kramer, George Martin, Jimmy Page, and Teo Macero. Evolving from the development of early sound and image technology, loops and looping made their presence known in the 196os through music recordings such as Steve Reich's It's Gonna Rain (1965), Miles Davis' Bitches Brew (1969), Terry Riley's Music for the Gift (1963), and Brian Eno and Robert Fripp's I97os collaborations. ${ }^{2}$ These early loop processes have now become the domain of digital sampling. Musicians have been impacted by looping through the development of loop pedals such as Memory Man, Ditto Looper, and Boomerang, and loop-based digital audio workstations like Fruity Loops and Ableton. Looping spills beyond the musical to film production and animation,

2 The early turntable experiments by John Cage and László Maholy-Nagy that can be thought of as proto-turntablism and sampling. As Zach Layton observes, in his 1922 essay Production-Reproduction Maholoy-Nagy "suggests that reproductive technologies, such as the gramophone record, could be reimagined as an artistically productive technology, creating sensory experiences that had never been possible previously. [Maholoy-Nagy] writes that since, it is primarily productive creation that serves human [physical, psychic, and sensory] development, we must seek to expand the use of apparatuses (means) used so far only for reproductive purposes to productive purposes as well"” (Zach Layton, "Moholy-Nagy and "Optical Sound" at the Guggenheim," Guggenheim Blogs, I8 July 2016, https://www.guggenheim.org/blogs/checklist/moholy-nagy-and-optical-sound-at-the-

guggenheim_(accessed 2r March 2019). For more on musical repetition and consumer culture see Robert Fink. Repeating Ourselves: American Minimal Music as Cultural Practice, Berkeley: University of California Press, 2005. doi:I0.I525/j.cttIpntqm.. For more on the technological development of studio practices and its impact on musical innovation, see: Paul Théberge. Any Sound You Can Imagine: Making music/consuming technology. Hanover, NH: Wesleyan University Press, 1997 and James Burgess, The history of music production. New York: Oxford University Press. 20I4. 
and it has a fundamental function in digital computing for running sequences of instructions to bring about specific conditions in the computing environment. Loops, then, have an important role to play in ordering the everyday flow of our consciousness and assembling our temporal and rhythmic interactions with machines, culture, and the social.

Basinski's compositional process begins with a visit to his archive of magnetic tape recordings made since the 1970s, which he refers to as "the land that time forgot." 3 These recordings are then played on various analog machines, occasionally transferred to digital, allowed to erode and decay, and performed live in concert. Basinski's works are generally composed from unspooling of various loops on magnetic tape, which he has accumulated and archived, and the real-time processing of these loops with delays and reverbs. ${ }^{4}$ In interviews, he has argued for an understanding of the loop and its repetition and duration as a critical component of memory and consciousness, stating that "memories are loops, our memories are made of loops. We have loops that constantly go around and around." How these loops go around and around as a form of memory or consciousness and how they connect to ideas about everyday events, duration, and the instant is a more obscure aspect of Basinski's practice that I intend to examine in this article. It does seem that a number of complex processes between the subject and technology are brought together in the relationship between the loop as a performative object and temporality, archives, and memory. ${ }^{6}$ In Basinski's practice, producing, storing, and playing back a loop is an important part of transmitting and transforming the consciousness embedded in the technologies that record, store, and play back memories, the passage of time, and experiences. Magnetic tape, as well as other forms of time-based media, are part

3 Ellis Jones, "The Slow Sublime and 9/Ir: Insecurity and Fear in William Basinski's The Disintegration Loops," Music and Politics, vol. 8, no. I, 20I4, full text available at https://quod.lib.umich.edu/m/mp/9460447.0008.IoI/--slow-sublime-and-9II-insecurityand-fear-in-william? $r$ gn $=$ main; view=fulltext (accessed 2r March 2019).

4 Pascal Savy, "William Basinski," Fluid Radio-Experimental Frequencies, n.d. http://www.fluid-radio.co.uk/2013/05/memories-are-loops-a-conversation-with-williambasinski/ (accessed 3o June 2018).

5 Ibid.

${ }^{6}$ Tilman Baumgärtel has analyzed loops in the context of the production of German dance music (this study is yet to be published in English); see Geert Lovink, "Dancing to the Loop: Repetition in Contemporary Music-An Interview with Tilman Baumgärtel," Dancecult: Journal of Electronic Dance Music Culture, vol.8, no. I, 2016, https://dj.dancecult.net/index.php/dancecult/article/view/908/777 (accessed 30 June 20I8). 
of our stream of consciousness and contribute to its construction and shaping, which in turn shapes our experiences through the processing of the flow of sensations and perceptions.

Basinki's compositions have gained a dedicated following since his $9 / \mathrm{II}-$ inspired series, The Disintegration Loops (2002-2003), became notorious for their lengthy mediation on decay and apocryphal connection to the September 2oor terror attacks. The Disintegration Loops have been read as an audio memorial that poses as a soundtrack to everything-from the repetition of everyday life to the impermanence of all things. 7 In many instances the degeneration of the medium of tape in Basinski's compositions is analyzed as a form of analog/digital transduction that highlights the instability of the loop and creates something new in the loop's repetition. In these readings, the loop and the process of disintegration are metaphors for being human. For example, Manuel Bogalheiro writes that "repetion as disintegration is thus the metaphor for the variations, unpredictabilities, deteriorations, hesitations, and delays that end up enabling human action and its choices of level." ${ }^{8}$ Other technological analyses address the modulation between analog and digital forms and draw attention to the fetishization of analog forms that constitute the material of "objectified, audible phenomena in electronic music, from notes and rhythms to sound grains, clicks, timbres, and even silence."9 Again, Basinski’s loops become

7 See, for example, Christopher Kempf, "The Disintegration Loops, and The Writing of the Disaster: After William Basinski," Colorado Review, vol. 42, no. 3, 20I5, p. 16I-63, full text available at https://muse.jhu.edu/article/602464/pdf (accessed 2o March 2019); Christophe Levaux, "William Basinski: The Disintegration Loops. From Memory to Oblivion," unpublished presentation prepared for the conference RMA Study Day: Memory in PostIg80s Music: History, Form, Perception, 22 February 2014, University of York, http://hdl.handle.net/2268/186542 (accessed 19 March 2019); Eli Stine, "Memory, Decay \& Activism: William Basinski's The Disintegration Loops," paper written for Matthew Burtner's course "Musical Materials of Activism," Spring 2015, http://elistine.com/blog/memory-decayactivism-william-basinskis-the (accessed I9 March 2018); Manuel Bogalheiro, "Disintegration and Repetition: An Analysis Based on William Basinski," Revista Lusófona de Estudos Culturais, vol.5, no. I, 2018, p. 293-305, full text available at https://repositorium.sdum.uminho.pt/bitstream/I822/55287/1/2018_RLEC_5.I.pdf (accessed 19 March 2019); Joanna Demers, "Ambient Drone and Apocalypse," Current Musicology, no. 95, 2013, p. 103-390, full text available at https://currentmusicology.columbia.edu/article/ambient-drone-and-apocalypse/ (accessed 19 March 2019).

${ }^{8}$ Bogalheiro, 2018, p. 304.

9 Joanna Demers, Listening through the Noise: The Aesthetics of Experimental Electronic Music, New York, Oxford University Press, 2010. 
caught up in the temporal processes of time passing and the melancholic "bereavement for life that has expired and cannot be resurrected." то The importance of the loop in these readings lies in the vibratory quality of musical sound for carrying meaningful associations and references of temporality and lived experience. But, as both Joanna Demers and Gareth Leaman argue, any reading of sound imposes such relationships on the material of the sound as "there is nothing inherent within the work itself to imply such a relationship." These arguments leave us at an impasse about the significance of Basinski's work.

These readings take attention away from other aspects of repetition and social processes in Basinski's work that are critical to understanding the relationships between technology, sound, and memory. The integrated processes that bring technology, memory, and music together have important implications to the relationship between sound reproduction technologies and the way they produce and reproduce temporalities and subjectivities, resisting what Tony Sampson has identified as neurocapitalism's “collective rhythmic entrainments." ${ }^{2}$ Entrained rhythms tie affective states, the experience of flow, to neurocapitalism through repetition and feedback that harness shared collective temporal experiences, which are synchronized to multiple industrialized temporalities of consumption, digital networks, and accelerated life in the twenty-first century. With this in mind, I am interested in situating Basinski's compositional techniques - by considering his recording Cascade (2015) and its live re-recording Deluge (2015) - as processes that resist, or at least complicate, the repetitions and synchronizations of collective entrainment by deploying other sustained rhythmic forces through repetition and delay. Basinski's long slow compositions are made with obsolete audio technologies and formats and the experience of them reshapes our notions of tertiary memory-memories stored and extended by cultural technologies like photography, cinema, and audiothrough the extended sonic experiences of repetition, feedback, and transformation. Basinski's compositions demand attention, and yet, we can easily slip in and out of the ambience they construct.

\footnotetext{
Iо Ibid. p. 63.

"G Gareth Leaman, "Memorials without Mimesis: Abstraction and Intertextuality in William Basinski's The Disintegration Loops," www.garethleaman.com, https://garethleaman.com/2015/05/17/memorials-without-mimesis-abstraction-andintertextuality-in-william-basinskis-the-disintegration-loops/ (accessed 19 March 2019).

${ }^{12}$ Tony Sampson, The Assemblage Brain: Sense Making in Neuroculture, Minneapolis, Minnesota, University of Minnesota Press, 2017.
} 
These extended periods of repetition and transformation differentiate Basinski's compositional practice from forms of repetition found in popular music. The popular music industry has enormous commercial and financial flows and the elevation of select performers to superstars. ${ }^{13}$ Further complicating this is capitalism's ability to absorb and normalize any opposition and turn it into profit. After complaining about revenue loss in the early 2000 , the global music industry has seen a 19.I percent rise in revenues since 2017 and has become a $\$ 9.4$ billion entertainment sector supported by consumption on a variety of distribution platforms. ${ }^{14}$ What differentiates Basinski is both an avant-garde stance as a composer opposing popular music forms and a non-teleological impulse that keeps the possibility of sound open rather than searching for narrative closure. As Robert Fink notes, "the simple vernacular of song carpentry-vamp, hook, drive, build, release-shows how deeply rock and pop are invested in directed motion forward." ${ }^{\text {Is }}$ The structure of the pop song usually

${ }_{13}$ Music studies has long been interested in issues of popular music and resistance. Differentiating Basinski's work from that of popular music studies would be the subject of another paper, but the literature on the relationship between sound and resistance is critically important for the present discussion. For just a few examples, see: Thomas Turino, Music as Social Life: The Politics of Participation, Chicago, University of Chicago Press, 2008; Greg Hainge, Noise Matters: Towards an Ontology of Noise, New York, Bloomsbury Publishing, 2013; Simon Frith, Performing Rights: Evaluating Popular Music, Oxford, UK, Oxford University Press, 1998; Keith Negus, Popular Music in Theory: An Introduction, Middletown, Connecticut, Wesleyan University Press, 1997; Daniel Fischlin and Ajay Heble (eds.), Rebel Musics: Human Rights, Resistant Sounds, and the Politics of Music Making, Montreal, Black Rose Books, 2003; Steve Goodman, Sonic Warfare: Sound, Affect, and the Ecology of Fear, Cambridge, Massachusetts, MIT Press, 20I2; Paul Gilroy, The Black Atlantic: Modernity and Double Consciousness, Cambridge, Massachusetts, Harvard University Press, 1993; Paul Gilroy, There Ain't No Black in the Union Jack, London and New York, Routledge, 2013; Lawrence Grossberg, We Gotta Get out of This Place: Popular Conservatism and Postmodern Culture, London and New York, Routledge, 2014; George Lipsitz, "Dangerous Crossroads," in Popular Music, Postmodernism and the Poetics of Place, London and New York, Verso, 1994, p. 10-38; Robin James, Resilience \& Melancholy: Pop Music, Feminism, Neoliberalism, Winchester, UK, John Hunt Publishing, 20I5; Robin James, The Conjectural Body: Gender, Race, and the Philosophy of Music, Lanham, Maryland, Lexington Books, 20Io; Tara Rodgers, Pink Noises: Women on Electronic Music and Sound, Durham, North Carolina, Duke University Press, 2010.

I4 "Global Music Report 20I8: Annual State of the Industry," International Federation of the Phonographic Industry, April 2or8, https://www.ifpi.org/news/IFPI-GLOBAL-MUSICREPORT-2018 (accessed 2r March 2019).

is Robert Fink, Repeating Ourselves: American Minimal Music as Cultural Practice, Berkeley, California, University of California Press, 2005, p. 32, italics in the original. 
signifies a movement towards a conclusion and resolution of its central narrative. Contrary to this Basinski's work seems to exist on a temporal continuum that we only listen in on and that creates an experience of listening to "audible portion of infinite lines." ${ }^{16}$ Basinski's pieces frequently fade in from nothingness or seem to be already playing when we encounter them. Thinking Basinski's work as infinite lines opens us up to thinking about the tape loop as a temporal form of repetitive media. But the line is not quite the right image, since the loop, and Basinski's use of it, continuously recurs and folds back in on itself. It may be a line in the narrative of a life or a particular recording, but on a more infinite plane the line becomes a spiral in its continuous return.

\section{TAPE AS AN INDUSTRIAL TEMPORAL OBJECT}

To have a loop, one needs to have a flexible storage device, such as a disc or magnetic tape that can record and play back repeated phrases. The versatility of magnetic tape lies in its flexibility and relation to easy production, reproduction, retrieval, and archiving and in its use for imprinting audio, visual, and data information. With the development of magnetic tape in Germany in the I920s, it became possible to cut, edit, and rearrange audio media (much like film) in different ways that allowed artists to reconstruct and re-edit what had already been recorded and stored. By cutting the tape and connecting the severed ends, the tape could be looped continuously as one phrase. The dominant format at the time, gramophone records, could be produced with various grooves that could be "locked," providing in this way a looped section that would play until the needle was lifted. Though early audio technologies are able to capture and repeat time, tape provides uninterrupted flexibility of format that shellac and plastic cannot.

Jonathan Sterne and Paul Hegarty have noted that the development of reproductive audio technologies like tape are intimately related to temporality. ${ }^{17}$ Commenting on the different ideas of temporality that have emerged with modernity and on the development of sound reproductive technologies, Sterne

\footnotetext{
${ }^{16}$ Brian Howe, "William Basinski Cascade/The Deluge," Pitchfork Media, 29 July 2015, https://pitchfork.com/reviews/albums/20900-cascade-the-deluge/ (accessed 2I March 2019).

${ }^{17}$ Jonathan Sterne, The Audible Past: Cultural Origins of Sound Reproduction, Durham, North Carolina, Duke University Press, 2003; Paul Hegarty, "The Hallucinatory Life of Tape,” Culture Machine, vol.9, 2007, https://oajournals.blogspot.com/2011/o2/culturemachine.html (accessed I9 March 2019).
} 
argues that such technologies trouble ideas of time as a linear industrialized object (labour time embedded in commodities), time as contained in the recording itself, and the "geologic time" of the medium itself and its unnatural lifespan. ${ }^{18}$ Sterne writes that the time stored by the recording medium is the "retention of a certain sequence, isolation, and repeatability of certain moments - a fragmented consciousness of time" in relation to a third temporality - "the decay of the recording itself, the ephemerality of the medium." ${ }^{19}$ For Sterne, theorizing the temporal aspects of audiovisual storage media comes down to the simple fact that the recording of a sound-or by extension, a picture or a moving image - is a storage of time. He complicates this understanding by noting that the sequence of time stored is neither linear nor eternal, but is a fragment taken out of time and prone to the decay of the physical medium itself. Tape is a part of our experience of time and exists in a relationship to the subject as a "temporal media object." For Sterne the temporalities introduced by new recording technologies bring together a machinic understanding of life in relation to the sense of decay that permeates human beings, but preserves the desire for something beyond the self. This insight advances an understanding of temporal media objects like gramophone records and magnetic tape as early forms of biomedia that bring the human into relationships with extended temporalities of storage mediums, and further connects to processes of consciousness as rhythmic entanglements of the machinic, social, and biological.

\section{LOOPING AS AN INDUSTRIAL TEMPORAL PRACTICE}

Bernard Stiegler has argued that consciousness and temporal media objects flow and intertwine, which causes them to coincide in their movement as they each

\footnotetext{
${ }^{18}$ Sterne, 2003, p. 310. Of course, the "life" of a magnetic tape is shorter than that of formats like shellac records and is subject to all kinds of environmental deteriorations. This is the central conceit of Basinski's The Disintegration Loops where the decay of the medium itself is captured in the processes of "death." There is also the geologic time of media developed by the contemporary theories of ecomedia and media archaeology best represented by Sean Cubitt and Jussi Parikka's work. See Sean Cubbit, The Practice of Light: A Genealogy of Visual Technologies from Prints to Pixels, Cambridge, Massachusetts, MIT Press, 20I4; Jussi Parikka, A Geology of Media, Electronic Mediations, vol. 46, Minneapolis, Minnesota, University of Minnesota Press, 2015.

is Sterne, 2003, p. 310.
} 
unfold their durations. ${ }^{20}$ So too, our experience of listening to Basinski intertwines our consciousness with his compositions, tangling our memory with the flow of his taped and performed sonic memories. The question about what constitutes a "temporal object" is a key one. Stiegler has made important inroads in theorizing the connections between technology, consciousness, and memory. For Stiegler a technical or media object becomes temporal "when its flow coincides with the stream of consciousness of which it is an object." Unsurprisingly, as its twentiethcentury development has been so closely associated with storage formats, music is a key object for enacting both temporality and memory in a biological and technological sense.

The concept of flow has a long and varied history in the social sciences and it is useful here to bring together Basinski's compositional and performance methods with the experience of listening to the synchronic and diachronic unfolding of the technologies that make up both his practice and our stream of consciousness. ${ }^{22}$ That is, the compositions enact an experience of flow, which occurs at some preconscious level of the self as it listens to the technologies that Basinski uses for his instrumentation, primarily magnetic tape and a variable-speed tape machine. The listening experience exists and evolves over time and is embedded in the technology of the magnetic tape loop played back by the recording device. Consequently, the flows of any of Basinski's compositions are inexhaustibly multiple or dialogic. ${ }^{23}$ There is the flow of Basinski's tape loops across the tape machine's heads and their subsequent deterioration with each passing; there is the matrix of temporal flows between the creation of the loops and their reactivation in various recordings and performances; there are the flows between the sound of the recording and the experience of the listener; and of course, the transactional

${ }^{20}$ Bernard Stiegler, Technics and Time, 3: Cinematic Time and the Question of Malaise, transl. by Stephen Barker, Stanford, California, Stanford University Press, 200 .

${ }^{21} \mathrm{Ibid}$. p. I.

${ }^{22}$ For a clear and comprehensive breakdown of the various usages and meanings of flow, see Stuart Alexander Rockefeller, "Flow," Current Anthropology, vol. 52, no. 4, Chicago, Chicago University Press, 20II, full text available at https://www.jstor.org/stable/ıo.Io86/6609I2?seq=I\#metadata_info_tab_contents (accessed 2I March 2019).

${ }^{23}$ I am using "dialogic" here to refer to a process of the self in relation to other things being experienced in and across temporalities, as derived from Mikhail Bakhtin and expanded on by Michael Holquist: "[for Bakhtin] 'self' is dialogic, a relation [...] self/other is a relation of simultaneity. No matter how conceived, simultaneity deals with rations of same and different in space and time" (Michael Holquist, Dialogism: Bakbtin and His World, London and New York, Routledge, 1990, p. 19). 
flows of purchasing or downloading the album. In performance, we experience the flow of his looped recordings and of processing the sound with reverbs and delays and digitally sampling the work. Temporally, there is the flow of time as these sounds encounter our consciousness and we experience them as well as the conjunction of our consciousness with the material objects of tape, machine, and composition. There is Basinski's carefully constructed narrative framing of his recordings through cover art, liner notes, and titles that often evoke natural images of rivers, cascades, and deluges connected to opaque memories, unidentifiable nostalgia, and obscure atmospheres. And of course, there is the repetition of these flows as they loop and return in our recursive memory, consciousness, and experience, mediated by the technological developments that connect biological memory to machines, storage formats, and personal archives.

In the transition from the nineteenth to the twentieth centuries, the moment in which temporal media objects began to intensify the industrialization of memory, Edmund Husserl examined the way temporal objects appear in our recollective experience of a memory by using the example of recalling a melody heard at a concert. Perceptibly, we have the first "in-the-moment" instance of experience, or primary retention, of the melody; it then gives way in the passing of time to a secondary continuum of apprehending the temporal object by representing it in our memory. This exchange of primary and secondary memory constitutes the flow of past and present that occurs in transition from the original hearing and subsequent recollections of the melody. The receding experience between primary and secondary memories provide us with our sense of the past: "[...] the temporal present in recollection is a remembered, re-presented present; and the past too is a remembered, re-presented past but not an actually present past, not a perceived past, not a past primarily given and intuited." ${ }^{24}$ By experiencing the primary instant that recedes into the secondary past as experience, we can project the possibility of the future. Husserl refers to these remembrances and projections as retentions and protentions, or simply the way our world appears to us through our sense of temporal flow, that is, we do not live discrete temporal moments, but experience time as a mostly connected experience. Retention occurs when a piece of what we have perceived is kept in our consciousness, though it is no longer immediately before us in perception. Protention projects a moment that is yet to be perceived, but that we may anticipate as possibly occurring. Thus, a temporal

${ }^{24}$ Edmund Husserl and John B. Brough, On the Phenomenology of the Consciousness of Internal Time (I893-1917), transl. by John Barnett Brough, Edmund Husserl-Collected Works, vol. 4, Dordrecht/Boston, Kluwer Academic Publishers, I99I, p. 38. 
object, like a song or a film, entangles with our consciousness when "an aggregate of primary retentions combined by the consciousness looks at or listens to the temporal object in various ways, where protentions and expectations are produced.” ${ }^{25}$ The loop complicates the experience of primary and secondary retention.

Stiegler states that our temporal experiences become the material of our memories: "[...] all those material contents (souvenirs) [...] together form the woven threads of our memory." ${ }^{26}$ A looped recording, such as Basinski's, constantly returns to its original melody as we perceive the music in the present, meaning we can, or should, anticipate what may be coming as a possible outcome. As a temporal object, the loop is experienced as a flow that involves retentive experience again in our immediate present and projects expectation or anticipation for the repetition of the sonic event in the future. As we move through our temporal experience of the loop, each protention becomes our immediate present to become the retention of the next. Within this matrix of temporality, we experience the recursive nature of memory through an industrial and technological object that plays with our experience of the past, present, and future and subsequently our experience of memory, immediacy, and futurability. Stiegler's souvenirs seem like a process of looping and harmonize the idea of weaving and gathering the threads of temporality with Basinski's claim that we are all loops.

\section{INDUSTRIALIZED MEMORY}

This is also where we come up against the limit of Husserl's analysis, which Stiegler extends by elaborating a theory of how time is industrialized and captured within temporal industrial objects like sound recordings, cinema, and computers. As media developed and intensified in the twentieth century, our memories rapidly became technologized and industrialized as objects that now precede our existence and the construction of our primary and secondary retentions. The industrialization of culture and memory has resulted in processes of increasingly complex and dense "exteriorizations" of our secondary retentions or memories. This has consequences not just for the individual subject, but also for the entire

${ }^{25}$ Bernard Stiegler, Symbolic Misery —Volume I: The Hyperindustrial Object, Cambridge, UK, Polity Press, 2004, p. 87.

${ }^{26}$ Bernard Stiegler, For a New Critique of Political Economy, transl. by Daniel Ross, Cambridge, UK, Polity Press, 2oio, p. 9. 
collective constitution of the world. Stiegler writes "a newborn child arrives into a world in which tertiary retention both precedes and awaits it, and which, precisely, constitutes this world as world." 27 With the technologization of our memories, it becomes possible to capture, record, play back, and archive numerous aspects of our memories via a number of formats, including magnetic tape, discs, and hard drives. With the rise of digital tertiary devices, the once avant-garde practice of cut, copy, and paste has become part of everyday software environments and a basic function of our interaction with the world. Subsequently, the manipulation and splicing of memories, both collective and individual, becomes a critical part of contemporary everyday life and labour, world making, and ultimately, sense making.

Stiegler's primary insight here is the way an industrial temporal object oscillates between primary and secondary retention and shapes the immediate experience of the melody and the application of memory through the imagination of a melody. Before sound recording, Stiegler argues, it was impossible to listen to the same melody twice. With recording, identical repetition has become possible, with a profound impact on how we remember and retain temporal objects. We can now easily remix tertiary memories or manipulate them through signal processing. A haze of familiarity and accelerated repetition characterizes the world and puts us at risk of losing our unique experiences of time as we become synchronized in our collective consumption of media.

Basinski's compositions function in the interplay of primary and secondary memories, in the activation and performance of tertiary memories stored in industrial objects. This creates a complex relationship between the subject's experience of the temporal object. As noted earlier, Basinski has conceptualized memory and subjectivity as a loop that we can now further complicate with insights derived from Stiegler. The practice of looping, which is simply a repetitive section of music, highlights the composition's flow through our perception and experience of the time-based media object. The loop is an ontological ground that makes memory and perception feed back into themselves and that in this instance we might define as the return to an earlier position or a reaction to that return.

As mentioned above, Basinski is not against using the digital to realize his compositions, but he does see something in the process of using tape that the digital cannot achieve. His 2015 recording Cascade provides a good example of these entanglements of temporal objects that loop time, memory, and perception.

\footnotetext{
27 Ibid.
} 


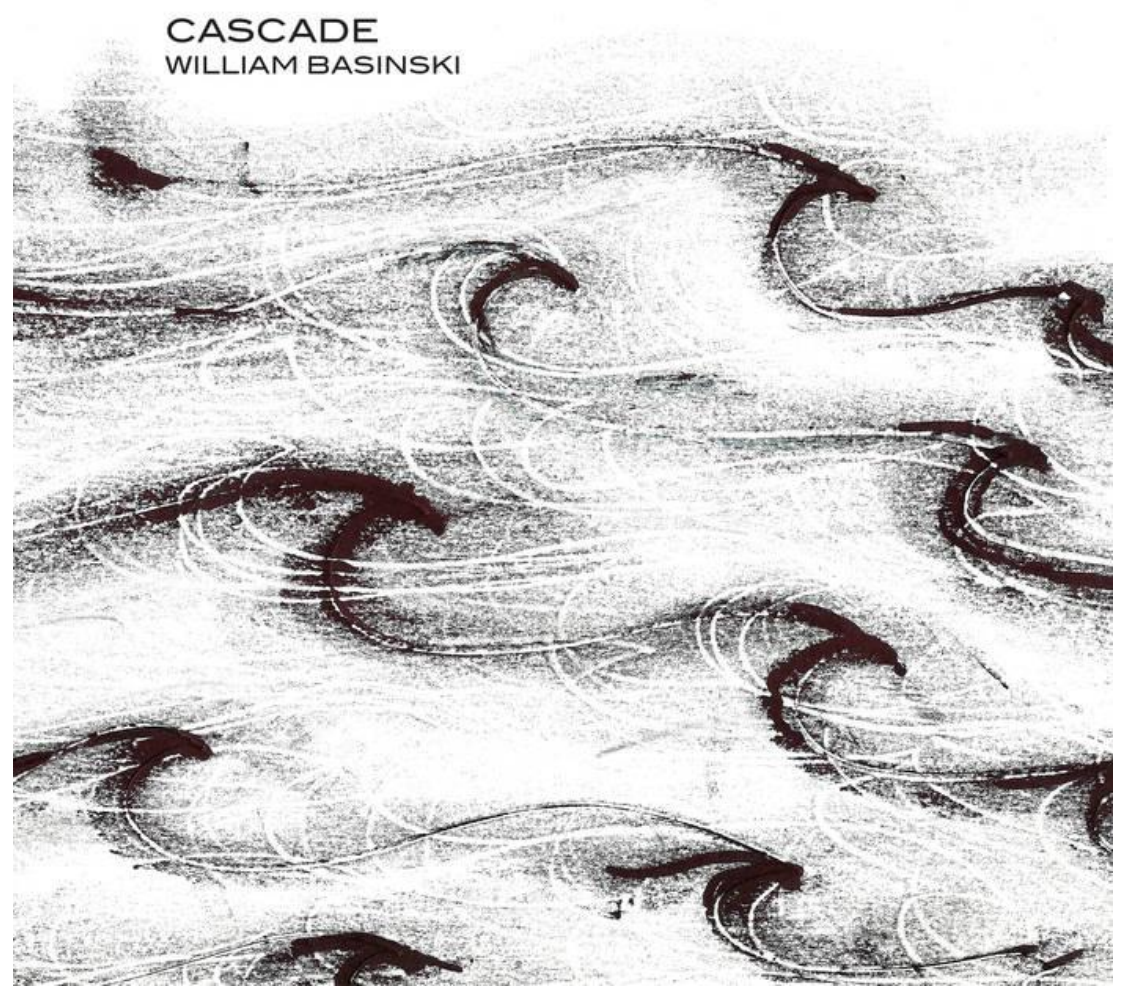

Soundtrack I: William Basinski, Cascade, 20I4, Los Angeles, Label: 2062; Published by Musex International (BMI): http://erudit.org/media/im/I06502Iar/1065021araool.mp3. https://www.mmlxii.com/products/545658-cascade;

https://williambasinski.bandcamp.com/album/cascade (accessed II September 20I9).

Courtesy of William Basinski.

The process is fairly simple: Basinski threads magnetic tape on to the machines, fading in from something obscure, yet familiar, letting the notes ring out, and enveloping them in delays that reverberate and shimmer, obscuring the melody, and making the time difficult to count. There is a ludic sense that resonates nostalgia with novelty and repetition with difference. Basinski's use of tape, analog and digital processing, and variable-speed tape recorders synchronizes the human with the machinic and our memory within the machinic process. But the recording also evokes an obscure emergent memory in the production of the murky and opaque textural haze that accompanies the notes sustained by delay and resonance. Listening closely 
to the motion of the tape as it is processed in the instant, our sense of time and affect asynchronously torque around each other in bewildering ways, confusing the industrial with the biological and pushing our perception out of time, arythmically. Human and technical memory waver between the synchronized and the nonparallel. This is best illustrated in the emergent subtlety of the temporal play of rhythm, texture, and timbre against the foreground of the piano notes in Cascade that becomes apparent in its live rendition Deluge.

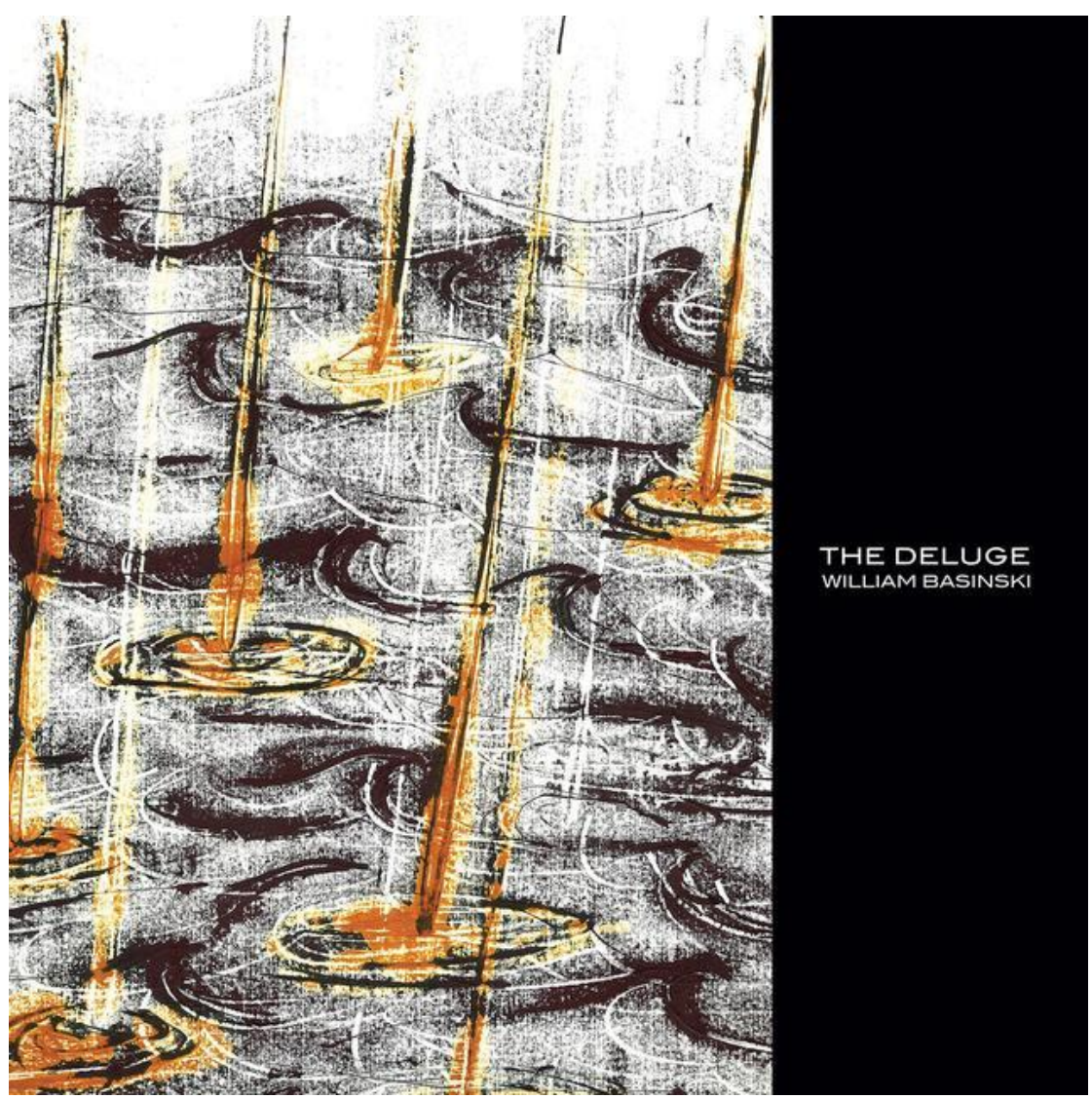

Soundtrack 2: Excerpt from William Basinski's The Deluge, 2015, Label: 2062; Published by Musex International (BMI): http://erudit.org/media/im/106502Iar/Io6502Iara002.mp3. https://www.mmlxii.com/products/546189-the-deluge;

https://williambasinski.bandcamp.com/album/the-deluge;

https://www.temporaryresidence.com/collections/william-basinski/products/trr258 (accessed II September 2019). Courtesy of William Basinski. 
Basinski disrupts the synchronization by processing the industrial object and tertiary memories in real time and by creating a background of delay and ambience that overtakes the tertiary level, opening up listening, a fundamental part of the senses, to an unfolding of multiple temporalities at the primary and secondary level. This forms a sonic cascade: simultaneously several sonic waterfalls pass through us, but are still arranged, patterned, and sequenced. The composition's re-imagining can be experienced as a layering of temporalities from Basinski's perceptual archive: the time and space of the recording, the time of the performance, the time of our listening, the repetition of this particular piano loop across Basinski's oeuvre, the stretching of time through the processing of the signal with reverberation and delay. The processing reconfigures the insistent return, the wandering of our consciousness that enlarges the frame of the composition to encompass the deep time of magnetic tape, the present time of listening, and the inconsistent flux and flow of the tape. Tape is a perfect medium to trouble the idea of linear chronology and perfectibility, which orders so much of our lives, and constructing instead a creative opening and expansion of possibility, simply because the medium of tape is imperfect in its analog fragility. Imperfection becomes possibility.

\section{Creative Temporal OBjects}

The question is what Basinki's deployment of his loops means within the context of the industrialization of memory, sensation, and perception. For both Stiegler and Basinski, the industrialization of temporality has led to catastrophe and misery. Stiegler relates this condition to the development of industrial temporal objects and the "hyper-synchronization" of the "we" who are "seriously ill." 28 The illness of the contemporary period is the loss of singular sense of subjectivity defined by Gilles Deleuze as the "dividual," a subject reduced to data and information contained in technological systems of control. ${ }^{29}$ The technologization or industrialization of our memories and consciousness has enormous ramifications for the world through the institution of the media and communications industry, which is now able to synchronize consciousness at global scales and synthesize memory and media signals with ubiquitous repetitions. Media markets are involved in the

\footnotetext{
${ }^{28}$ Stiegler, 2004, p. 60.

${ }^{29}$ Gilles Deleuze, "Postscript on the Societies of Control," October, vol. 59, 1992, full text available at https://www.jstor.org/stable/778828?seq=I\#metadata_info_tab_contents (accessed 2I March 2019).
} 
exchange of consciousnesses, or what we may more commonly refer to as the attention or audience economy in which music has a privileged position.

It is in the industrialization of sensibility and music's privileged position as a media, identified by Stiegler in volume two of Symbolic Misery, that we find parallels with looping and Basinski's work. For Stiegler, the technologization of music occurs as a double movement of new emerging technological practices and their impact on being a creative artist: "in all the arts, instruments, machines, and modes of notation and recording are now visibly proliferating, ceaselessly redefining artistic practices." 30 But music, unlike cinema, has a history that was not machinic and instead originates in the subject's experience of the body's resonance. The question of music's foundational resonance as a vibrational consciousness pushes Basinski's compositions up against the very foundation of being threatened by the industrialization of temporality. In a very material sense, the slow temporal unfolding of Basinski's loops becomes sonic tactics in the war over capturing perception and sensation. Techniques developed in the twentieth century around advertising and marketing have found their logical outcomes in the establishment of neuromarketing and algorithmic processes contained in much of our digital existence. Controversially, the battle over the "neuron" and the success of neurotypicality, which can be exploited by social media corporations like Facebook who are interested in developing triggers that increase the likelihood and predictability of behaviours, has become more urgent since the revelations of the 2016 American election, the claims of predictive corporations like Cambridge Analytica, and the reports about cyberwarfare capturing hearts and minds. ${ }^{3 \mathrm{I}}$ The veracity of these claims is less important than the understanding that the tactical projection of these corporations resides in the hope of industrializing sensation and perception to drive collective behaviour towards predictable consumption and obedience. These revelations, along with the twenty-first century's post-9/II, post-2008, smartphone-controlled, social-mediatized, and networked ontologies have embedded our subjectivity in atmospheres and temporalities where the affective dimensions and the resonances between self, technology, and temporality are connected to the decay of democracy and the increased impotence of possibility. The decay of possibility is the

30 Bernard Stiegler, Symbolic Misery-Volume 2: The Catastrophe of the Sensible, Cambridge, UK, Polity Press, 2005, p. 7.

${ }^{31}$ For work on this tendency in social media see Franco "Bifo" Berardi, Breathing: chaos and poetry, South Pasadena, CA: Semiotext(e), 2018; Giorgio Griziotti, Neurocapitalism: technological mediation and vanishing lines, 2019; Gerald Raunig, Dividuum: machinic capitalism and molecular revolution, South Pasadena, CA: Semiotext(e), 2016. 
contemporary condition identified by Franco "Bifo" Berardi, who has written extensively about the "age of impotence" and the post-future era that is upon us. For Berardi, the contemporary period is unequivocally instigating a change in the circuitry of the human, which is doing irreparable harm to people's attention span and ability to live authentic lives. Berardi characterizes the post 9/I period as a global civil war that has been waged through the dominance and ubiquity of digital capitalism to automate our habits and responses through algorithmic repetition that entrains our cognition to repeat and control certain actions. The automation of our cognitive abilities have brought about a world characterized by increases in panic, pornography, overstimulation, automation, artificiality, acceleration, digitization, speed, suicide, among other affective states. ${ }^{32}$

In one sense, loops are a perfect consumer commodity object of repetition and habit, as Fink has argued. ${ }^{33}$ Basinski is aware of his role of creating counter temporal experiences, which positions the creative temporal object as an experience in opposition to the industrialization of temporality. What is happening here could be called a re-attunement of our sensibility or the opening of the subject's temporal experience to the infinite relation of space and time. The political aspect of Basinski's music is not to simply immerse us in the cosmic flow of his repetitions and lose our selves, but to work as a kind of counter-production or counter-frequency to the capture of memory in industrial objects, which works against the accelerated flows and rhythms of industrial capitalism, and the capture and explosion of our attention to machinic processes. Berardi argues that the mental sphere is being reformatted to the uncompromising demands of digital capitalism, which is also a reformatting of the emotional sphere. ${ }^{34}$ Arguably then, if the media can format the body and the senses by industrializing memory and experience, then a reformatting can be possible as well by creating new sensations and perceptions through art's reconfiguration of perception and sensation. ${ }^{35}$ Rather than a synchronization, there is an oscillation or the opening of possibility. The material for the composition and recordings consists of industrial temporal objects, but Basinski's manipulation and intervention with them disrupts the synchronized flow of the loops. Rather than a movement of exact

${ }^{32}$ Franco "Bifo" Berardi, Futurability: The Age of Impotence and the Horizon of Possibility, London and New York, Verso, 2017, p. 23I.

33 Fink, 2005.

34 Franco "Bifo" Berardi, And: Phenomenology of the End: Sensibility and Connective Mutation, South Pasadena, California, Semiotext, 2015, p. 89.

35 Stiegler's thinking along these lines echoes Gilles Deleuze and Felix Guattari's work on perception and subjectivity. 
repetition of tertiary retention, memory gets played and redeployed: the flow changes course, the mind gets changed.

For Stiegler, the artist is the figure who joins the individuated "I" and forges it with a "we" through a process of opening and widening of potential. These processes are an important part of the flows of the stream of consciousness as it encounters industrial temporal objects, which for Stiegler constitutes the contemporary turmoil of industrialized temporality. Stiegler writes that the process is a "flow which is itself made up of vortexes: vortexes are spiral flows within flows where they form endless counter-currents. The counter-currents, however, return to the current according to their singular curve, and are thus the (deep and superficial) reality of the dominant current, of the 'flow'." ${ }^{6} 6$ It is this production of possibility within the flow that I hear going on in Basinski's work; it uses the loop as a form of critical practice (sometimes successfully, other times not), which builds a context for "becoming" in tandem with processes affirming the importance of the production of collective cultural temporal objects. Repetition, habit, and novelty are all part of the loops that expand these realities and provide a sense of the rhythmic form or processes of our worlds in interaction, opposition, and synchronization. What Stiegler seems to be proposing is the role of the artist as a reformatting of the temporality of being and the sensibility of the individual through a process of counter-flows, counterrhythms, and the aesthetics of production. Resistance occurs at the level of the individual, the collective, and through making things that challenge or change synchronized mass repetition. ${ }^{37}$ Basinski's out-of-sync loops and out-of-time archive are chaotic and extraordinary; the duration of his work has infinite potential and his dynamic processing opens the repetitions of his loops up to infinite expansion and possibility: in short, to the experience of something extraordinary.

\section{CONCLUSION}

Commenting on the "bad feedback" in the world today, Basinski positions his works as a salvo in the battle for the recomposition of the mental sphere through the deployment of counter-loops. In the interview with Pascal Savy where Basinski compares the self to loops, he continues:

\footnotetext{
${ }^{6}$ Stiegler, 2005, p. 154.

37 "The experience of the sensible opened by the work is the experience of a temporal ecstasy strictly speaking," Stiegler, 2005, p. 163.
} 
Basinski: Feedback needs to be surfed, you have to be very careful if you want to work with feedback because otherwise it just destroys everything. We're at a point right now where we need to get rid of some bad feedback loops, and it's happening. It's not gonna be pretty, but eventually things will resolve [...]. Or we won't survive. Good riddance to bad rubbish, as far as I'm concerned the human race is not taking care of the planet, it's only taking care of itself. So if it destroys itself, well, too bad! The planet will survive... We're too selfish and spoiled.

Pascal Savy: What is the place of your music in all of that?

Basinski: It's the only thing I can do, this is my way of changing the resonant frequency... it's war. ${ }^{38}$

It is in this space and time that Stiegler argues for the work of art as a support for the dissolution of the self-obsessed, distracted, accelerated, and fragmented subject and for the reactivation of the mental sphere. Good art should be a form of therapeutics and music has a privileged role to play in the arts in restoring the self back to itself in a process beginning again - a refreshment of the self. Stiegler argues that listening to music can be a miraculous experience,

which brings me back to myself, but as an other: making me become what I am with a strange feeling of becoming again what I am-of coming back to myself, but as the difference of my repetition, as though I have regained consciousness. [...] I then feel I am taking back my time while being taken back into time, by time, feeling myself individuate, myself anew, again, da capo. 39

Temporal media objects and consciousness both have movement that coincide as they uniquely unfold in their durations. Listening to Basinski weaves our consciousness with his composition, and tangles the experience of our memories with his archives and tapes. The result is an activation of Basinski's archive that becomes a part of both the creative temporal flow of the media object and the flow of our consciousness of it. Basinki's compositions affect our notions of tertiary memory by having us conceptualize the loop's repetition and duration as a critical component of memory and consciousness.

$3^{8}$ Savy, n.d.

39 Stiegler, 2005, p. 164 (emphasis in original). 


\title{
Repetition, Feedback, and Temporality in Two Compositions by William Basinski
}

\author{
David Christopher Jackson, Carleton University
}

\section{ABSTRACT}

In this essay I examine how William Basinski's loop-based recordings reveal and extend the aesthetic concurrence between technological, biological, and human duration, memory, and the perception of the industrial temporal object. The examination of how looping stresses a composition's flow in the perception of a timebased media object and the exchange between memory and the machine as a performance and configuration of the mental sphere, pursues a line of thought that brings together ideas about repetition in Basinski's compositions as a sonic reformatting of the mental sphere and the technology of Basinski's slow, analog, compositions contra the accelerated digitalism of twenty-first-century life.

\section{RÉSUMÉ}

Dans cet article, j'examine comment les enregistrements en boucle de William Basinski révèlent et étendent la concurrence esthétique entre la durée technologique, biologique et humaine, la mémoire et la perception de l'objet temporel industriel. Examiner comment le bouclage souligne la circulation d'une composition dans la perception d'un objet médiatique temporel et l'échange entre la mémoire et la machine comme performance et configuration de la sphère mentale poursuit une ligne de pensée qui rassemble les idées sur la répétition de la composition de Basinski, le reformatage sonore de la sphère mentale pour connecter la technologie des compositions lentes et analogiques de Basinski contra le digitalisme accéléré de la vie du $2 \mathrm{I}^{\mathrm{e}}$ siècle.

\section{BIOGRAPHICAL NOTE}

David C. Jackson received his PhD from Western University in 2016. He is an instructor in the Department of Communications and Media Studies at Carleton University where he teaches courses on screen culture and media piracy. His current research explores historical and conceptual experimental audio-visual media and their relationship to affect, poetics, and media aesthetics. His writing has appeared in Evental Aesthetics and Topia. 